\title{
A systems psychodynamic description of clinical psychologists' role transition towards becoming organisational development consultants
}

\begin{tabular}{|c|c|}
\hline \multicolumn{2}{|c|}{$\begin{array}{l}\text { Authors: } \\
\text { Frans Cilliers }{ }^{1} \\
\text { Sanchen Henning }^{2}\end{array}$} \\
\hline \multicolumn{2}{|c|}{$\begin{array}{l}\text { Affiliations: } \\
{ }^{1} \text { Department of Industrial } \\
\text { and Organisational } \\
\text { Psychology, College of } \\
\text { Economic and Management } \\
\text { Sciences, University of South } \\
\text { Africa, Pretoria, South Africa }\end{array}$} \\
\hline \multicolumn{2}{|c|}{$\begin{array}{l}{ }^{2} \text { Graduate School of } \\
\text { Leadership, University of } \\
\text { South Africa, Midrand, } \\
\text { South Africa }\end{array}$} \\
\hline \multicolumn{2}{|c|}{$\begin{array}{l}\text { Corresponding author: } \\
\text { Frans Cilliers, } \\
\text { franscilliers1@gmail.com }\end{array}$} \\
\hline \multicolumn{2}{|c|}{$\begin{array}{l}\text { Dates: } \\
\text { Received: } 24 \text { Feb. } 2021 \\
\text { Accepted: } 12 \text { Apr. } 2021 \\
\text { Published: } 07 \text { June } 2021\end{array}$} \\
\hline \multicolumn{2}{|c|}{$\begin{array}{l}\text { How to cite this article: } \\
\text { Cilliers, F., \& Henning, S. } \\
\text { (2021). A systems } \\
\text { psychodynamic description } \\
\text { of clinical psychologists' role } \\
\text { transition towards becoming } \\
\text { organisational development } \\
\text { consultants. SA Journal of } \\
\text { Industrial Psychology/SA } \\
\text { Tydskrif vir Bedryfsielkunde, } \\
47(0) \text {, a1891. https://doi. } \\
\text { org/10.4102/sajip.v47i0.1891 }\end{array}$} \\
\hline \multicolumn{2}{|c|}{$\begin{array}{l}\text { Copyright: } \\
\text { (c) 2021. The Authors. } \\
\text { Licensee: AOSIS. This work } \\
\text { is licensed under the } \\
\text { Creative Commons } \\
\text { Attribution License. }\end{array}$} \\
\hline \multicolumn{2}{|l|}{ Read online: } \\
\hline 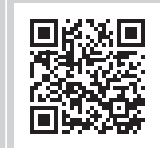 & $\begin{array}{l}\text { Scan this QR } \\
\text { code with your } \\
\text { smart phone or } \\
\text { mobile device } \\
\text { to read online. }\end{array}$ \\
\hline
\end{tabular}

Orientation: Clinical psychologists' transition from practising in a clinical context to a large organisation implies an intensely experienced professional identity shift.

Research purpose: To provide a systems psychodynamic description of the lived experiences of a group of clinical psychologists' role transition towards becoming organisational development (OD) consultants.

Motivation for the study: Although the role of clinical psychologists in organisations is theoretically explicated, limited research exists on their role transition experiences. Their lack of theoretical knowledge about and experience in organisational psychology make them vulnerable for exclusion and isolation.

Research approach/design and method: A hermeneutic phenomenological research design using a collective case study, consisting of eight clinical psychologists, was used. The data gathering methods included a Listening Post and socio-analytic interviews. Systems psychodynamic data analysis was performed.

Main findings: The manifesting themes related to experiences of diverse and intense anxiety, defensive structures, role, task, boundary and authorisation conflicts as well as solitary pilgrimages. Participants experienced an attack on their personal and professional identities, a sense of being overwhelmed, excluded and isolated from their colleagues and peers.

Practical/managerial implications: The findings will facilitate clinical psychologists' transition into OD roles and organisations' awareness of their identity challenges.

Contribution/value-add: Although employing clinical psychologists in OD roles is practised in many large organisations, the findings suggest that their transition into this role is underestimated in terms of emotional intensity.

Keywords: clinical psychologists; role transition; OD consultant; systems psychodynamics; qualitative; hermeneutic phenomenology.

\section{Introduction}

Organisational development (OD) is an established function in organisations tasked to optimise organisational functioning and relationship building. Organisational development is mostly populated by staff members with academic qualifications, experience and competence in human resources and organisational psychology (OP). Large organisations also often employ clinical psychologists (CPs) in OD consultant roles.

The Professional Board for Psychology as a division of the Health Professions Council of South Africa (HPCSA) (www.hpcsa.co.za) recently reviewed its scope of practise. The review included the discontent over CPs crossing the boundary into industrial psychology, whilst industrial psychologists (IPs) are not allowed to cross over into clinical work. Although this matter may be seen as contextual in this research, the focus is on the lived experiences of CPs during their transition into the world of OP.

The HPCSA category of industrial psychology (academically known as industrial and organisational psychology [IOP]) is defined as the science and practise of professionals functioning in organisational and occupational settings. Their task is to ethically explain, assess and influence 
human behaviour, its reciprocity at individual, group and organisational levels, aiming to direct human flourishing and the sustainable development of all affected stakeholders (www.hpcsa.co.za). As a subdivision of IOP, OP studies individual assessment and interventions to change problematic behaviour towards optimal individual, group and organisational functioning (Berg \& Geldenhuys, 2013). In addition, the dynamics towards the promotion of employee wellness and productivity, as well as organisational behaviour in terms of structure, design, culture, change, job satisfaction and leadership development are within the scope of practise of IOP (Schreuder \& Coetzee, 2010).

Within OP, OD functions as a scientific behavioural discipline, a field of practise and consultation, concerned with longrange multifaceted change programmes, processes and interventions, primarily of a planned and sustainable nature. Its purpose is to enhance the adaptive and self-renewing capabilities of organisational systems in response to, or in anticipation of shifts in the needs and demands of clients, as reflected by diagnostic data. The data are generated mainly through the application of behavioural science knowledge and technology and interpreted through collaborative and collective sense making and learning processes (Brown, 2014; Viljoen, 2015). Organisational development is based on respect, trust, support and participation as values and acts as a container for the planning, design and implementation of organisational change strategies. Various methodologies are used (e.g. action research) to bring about technical, structural, behavioural and social change in organisations (Robbins \& Judge, 2009). Most OD consultants work systemically on the individual level (e.g. executive coaching), group level (e.g. team coaching) and organisational level (change management, transformation) in active participation with a variety of internal and/or external stakeholders (Lowman, 2016).

The HPCSA category of clinical psychology is defined as a specialist category within professional psychology. The task is to provide continuing and comprehensive mental and behavioural healthcare to individuals and groups across the lifespan. This includes the assessment, diagnosis, evaluation and treatment of psychological and mental health disorders ranging from mild to severe and complex. Psychological assessment, diagnosis and formulation are based on biological, social and psychological factors. Clinical psychologists deliver a range of high-intensity psychological interventions with demonstrated effectiveness in treating mental health disorders and psychological distress associated with medical conditions (www.hpcsa.co.za).

Although organisational consulting psychology (OCP) is not a recognised HPCSA registration category, it has become a field of study and practise of integration of the knowledge and organisational applications from various psychological disciplines including organisational, clinical and social psychology (Berg \& Geldenhuys, 2013; Lowman, 2016). Organisational consulting psychology is defined as the application of psychological knowledge to organisational behaviour, advising individuals, groups and organisations as a whole to work more effectively in creating conditions of high satisfaction, motivation and effective relationship building (Levinson, 2009; Lowman, 2016).

\section{Literature review}

\section{The role of the clinical psychologist in organisations}

Although OD was recognised in large international organisations since the 1970s, it did not yet function from a systematic body of professional knowledge. During this time, Levinson (1972) published his seminal work on the extrapolation of clinical diagnostic methods from the individual to the organisation. He integrated individual and group (collective) psychology, applying personality, motivational, leadership, small group and open system theories, as well as a range of therapeutic interventions. He then encouraged CPs to join OD divisions in the role of organisational diagnosticians, consulting to the conscious clarification of employees' feelings and perceived problems as well as the understanding of unconscious behavioural processes. This included defences such as resistance and transference towards consultants. Levinson's (1972) work laid the foundation of a scientific OD consultancy in a fivestep procedure, namely (1) a study of the history of the systems, (2) a study of the present system (organisational structure, physical facilities, people, finances, practices, procedures, policies, values, technology and context), (3) interpretation of the consultant's observations (interviews, psychometric data, management of information, personality characteristics of dominant role players and style of the organisational personality), (4) the above summarised in an interpretive diagnosis and a working hypothesis about what may be manifesting in the system and (5) a feedback report to the system to establish a basis for action in the format of intervention methods to test the hypothesis or revise the hypothesis and its methods towards solving the problem.

Consulting to organisational culture from a clinical descriptive approach consisting of systemic observation (similar to the socio-technical approach developed at the Tavistock Institute) was also suggested by Schein (1990, 2013). Later, Levinson $(2002,2008)$ suggested that organisational consultants should preferably use a broad organisational assessment stance. This focus is on systemically studying individuals, executive selection, career development, coaching and leadership, informed by psychoanalytic and organisational theory, dynamics of personality development, emotions, motivation, irrational and unconscious feelings, thoughts and behaviour.

In some countries, CPs in OD roles are referred to as consultant CPs (Miller, 2018) which require a doctorate in psychology and experience in clinical, counselling, industrial-organisational and consulting psychology. This role combines clinical practise with organisational consultancy work, providing assessments, evaluations and advice. No such training exists in South Africa. In South African universities, the CP curriculum contains no 
reference to $\mathrm{OP}$ or OD. Thus, $\mathrm{CP}$ training does not prepare the psychologist to work with organisational systemic dynamics, integrating human relationships (people matters) with business strategy (the task) (Viljoen, 2015). The closest to such training is the $\mathrm{PhD}$ in consulting psychology at the University of South Africa (UNISA) which includes a general and integrative view on organisational consulting.

Although the present OD literature (Brown, 2014; Viljoen, 2015) does not differentiate between roles for clinical and other psychologists, Schein $(1999,2016)$ differentiated between directive versus non-directive OD approaches. A directive approach refers to a task focus such as proposing guidelines, persuasion and directing problem solving, performed by the OD consultant in an expert and informing role. A nondirective approach refers to process facilitation and consultation focussing on observation and raising questions for reflection about problem solving. Non-directionality is different in its complexity, requiring knowledge and competence in various psychologies (including clinical). It focusses on the building of client relationships characterised by a personal connection, openness, authenticity, curiosity and humility (Schein, 2016). This role implies using the self as an instrument (Cardona, 2020).

\section{Systems psychodynamic role transitioning}

The OD role is discussed in standard OD textbooks mostly from a positivist, rational, mechanistic and psychometric stance (Kilburg, 2012). However, to study dynamic, complex, uncontrollable, unpredictable, unconscious systemic organisational behaviour prevailing in resistant, regressive and emotionally charged situations, Levinson (2009) and Schein (2016) suggested a systemic and psychodynamic stance. This gives the OD consultant access to in-depth organisational diagnosis, process consultation, sociotechnical and structural changes and dynamic team behaviour from a systemic framework (Cardona, 2020).

Systems psychodynamics (SP) is a depth psychology, organisational consulting, coaching and research stance (French \& Simpson, 2015), based on social psychoanalysis, group relations, object relations, the notions of social structures as defences against anxiety, group-as-whole, the well-known iceberg model (Cardona, 2020; Layton \& LeavySperounis, 2020) and the psycho-social research approach (Clarke \& Hoggett, 2009). As such it studies the manifestation of systemic and dynamic conscious-rational and unconsciousirrational behaviour in organisations (Brunner, Nutkevitch, \& Sher, 2006).

In SP, transition implies a change in identity which refers to what gives rootedness to one's life (Freud, as quoted by Frosh, 2011). Furthermore, it represents the outcome of individuation, it is the sum of the representations of the self and forms a part of the ego related to narcissism that holds continuity and the ability to remain the same despite changes (Arundale, 2017; De Mijolla, 2005). Frosh (2011) defined identity as the personal essence or core of a consciously recognisable selfhood and a private, unknown and unconscious internal arena. Identity also refers to one's subjective experience of a persistent sense of sameness within oneself (Akhtar \& Twemlow, 2018). Erikson (1980) defined ego identity as the unconscious quest for personal and existential continuity and the synthesis of the ego. In terms of human development, identity starts from birth with somatic experiences of pleasure and unpleasure formed through one's primary intersubjective relationships (Verhaeghe, 2008). Taking-up organisational roles imply having a plurality of context-dependant hierarchical, salient and dormant identities (Vansina \& Vansina-Cobbaert, 2008). Employees are constantly moving back and forth between their private, social, role and organisational identities (Passmore, Peterson, \& Freire, 2013). Kets De Vries, Korotov and Florent-Treacy (2007) described such changes as being between identities which are typically experienced as being suspended, in no human's land, in the middle and having to cope with a stumbling block on the road to personal and professional transformation. At the same time, this situation serves as a transitional space (Winnicott, 2006) - an opportunity for heightened awareness, creativity, selfdiscovery, experimentation, examining of past and developing new identities. This process needs safe and caring psychological boundaries. Systemically, organisational identity refers to the totality of repetitive patterns of individual behaviour and interpersonal relationships that collectively comprise the unacknowledged meaning of organisational life (Allcorn \& Stein, 2015). Thus, the collective identity consists of employees' conscious and unconscious thoughts and feelings and the transferences (including connections, attachments and understanding) manifesting beneath visible organisational structures.

Smith, Crafford and Schurink (2015) studied the shifts in work identity amongst researchers from a conscious and rational perspective. No research on the unconscious identity experiences of employees during transition could be found.

During high levels of particularly survival anxiety, the shadow side of identity manifests in various defences such as denial, misrecognition, losing a sense of one's boundaries and a capacity for narcissistic masquerading (Arundale, 2017; Frosh, 2011). The experience of one's identity being under attack manifests as the diffusion of the self, the disintegration of representations of the self and the object and acting out behaviour (Erikson, 1980). On the macro level, the shadow side of organisational identity manifests when the system through leadership engages in subtle coercive practises that subjugate employees to subscribe to the prevailing idealised identity. Thus, employees can be drawn into a collusive, regressive psychological relationship with the organisation and its powerful and narcissistic dependency needs. Kets De Vries (2006) referred to this scenario as identity deformation.

\section{Problem statement, purpose, aim, contribution and layout}

The role of CPs in OD is historically explicated in terms of context, content, structure and complexity. Yet, no research 
could be found indicating whether in practise organisations consciously and deliberately differentiate between tasks assigned to IPs and CPs. It could be argued that the registration category boundaries are not strictly applied in OD and that all psychologists work within OCP. Furthermore, research on the experiences of CPs transitioning to OD roles is limited. Only one article (Liebowitz \& Blatter, 2015) could be found which provides steps of 'how to become' an OD consultant and an executive coach. No mention is made to their lived experiences.

The research purpose was to investigate the professional identity shift for CPs becoming OD consultants. The aim of the research was to provide a systems psychodynamic description of the lived experiences of a group of CPs' role transition towards becoming OD consultants. The contribution of this research is to create an awareness about and to offer a deep understanding of these experiences. The rest of the article consists of the research method, the findings presented per interview question, the discussion containing the extracted themes, practical implications, limitations and recommendations. Lastly, the conclusion is formulated.

\section{Research design}

\section{Research approach}

Qualitative and descriptive research in the psycho-social tradition was performed (Clarke \& Hoggett, 2009). A participatory action research approach (Terre Blanche, Durrheim, \& Painter, 2006; Thorne, 2016) was chosen based on the ideas of promoting knowledge about social systems, promoting well-being, using collaborative relationships and mediating between individual and collective needs. This approach served to ensure continuous connectivity, effective communication and active researcher involvement towards an understanding of participants' lived experiences (Wagner, Kawulich, \& Garner, 2012). Hermeneutic phenomenology was chosen as an interpretive stance to facilitate the understanding and interpretation of the frames of reference of the observer and the observed (Clarke \& Hoggett, 2009). The epistemological assumption is that empathetic listening allows for deep understanding of shared experiences (Alvesson \& Sköldberg, 2010).

\section{Research strategy}

The strategy comprised a collective case study with the unit of analysis being the participant group-as-a-whole (Wilson \& MacLean 2011). Thus, data analysis and interpretations are presented for the case as a collective.

\section{Research method}

\section{Research setting}

The research was performed amongst various large South African organisations with well-established OD divisions, and which included CPs as OD consultants.

\section{Entrée and establishing researcher roles}

Both researchers are psychologists (an IOP and a research psychologist), academics and external OD consultants. In these roles, they became aware of how CPs in OD divisions seemed to experience similar difficulties related to fitting into their organisational roles. Being trained as systems' psychodynamically informed consultants and researchers, they became curious about the unconscious causes of the experienced symptoms (Layton \& Leavy-Sperounis, 2020).

\section{Sampling and research participants}

Purposive and deliberate sampling was used (Thorne, 2016) consisting of eight CPs, all registered with the HPCSA for between 6 and 9 years. They started their professional careers in clinical positions in hospitals, resigned and joined their present organisations as an OD consultant and have been in these roles for at least 4 years. The sample consisted of women (4), men (4), black people (3), an Indian person (1) and white people (4), with an average age of 38 .

\section{Data collection}

\section{Step 1: A systems psychodynamic Listening Post}

The systems psychodynamic Listening Post (SPLP) (Long, 2013) is an unstructured group method based on the notion that the group's experiences allow for the understanding of the collective system. The whole sample attended the event that was digitally recorded. The first author acted as a convenor of this event, following standard SPLP directions (Stapley, 2006) with reference to managing task, time and space boundaries. The SPLP consisted of two parts. Part 1 (60 min): Participants were invited to share and free associate about their experiences in transitioning from a previous clinical psychology role to an OD role in their present organisation. Part 2 (30 min): Participants were invited to collectively and retrospectively identify the main themes that manifested in part 1 of the SPLP.

\section{Step 2: Determining the validity of the transitional questions}

Conceptual analysis (coding of the text into manageable content categories) (Sekaran \& Bougie, 2018) was applied to the SPLP part 1 data towards the researchers' understanding of the content. Next, relational analysis (exploring the relationships between categories in the data) was applied to the SPLP part 2 data to ensure face validity and congruence (Thorne, 2016) between part 1's content and part 2's formulated themes (which was found to be congruent). The researchers re-formulated these themes into questions (for interview purposes). The questions were: (1) What motivated you to transition from clinical to organisational psychology?, (2) What were your experiences in crossing the boundary into your organisation?, (3) What were your experiences in crossing the boundary into organisational psychology? (4) How are you coping in your role as an OD consultant?, (5) What characterises your new professional role identity?, (6) What is your contribution to the organisation? 


\section{Step 3: A 60-min individual socio-analytic interview}

This qualitative in-depth interview (Long, 2013) uses an existential and phenomenological approach to uncover, understand and hypothesise about thoughts and feelings related to unconscious systemic processes and dynamics that support, obscure and influence experiences. Participants are provided the space to 'think the unknown known' and to access the unconscious infinite (Schafer, 2003). The interviewer's responses include observation, active listening, clarifying, challenging, empathising, encouraging free association and notetaking. The interview consisted of an introduction (explaining purpose, conditions and ethics), the above six (SPLP generated) questions asked in succession and a review of the conversation. Interviews were conducted per appointment by the first author in a boardroom, digitally recorded and transcribed.

\section{Data analysis}

Simple hermeneutics (Clarke \& Hoggett, 2009) was applied to the interview data that facilitated an understanding of the lived experiences of participants (reported per question under findings below). Double hermeneutics comprising the application of the SP lens was applied to the SPLP part 1 data as well as the interview data that facilitated six SP themes (reported under discussion below). The data were integrated and encapsulated in the conclusion (Huffington, Armstrong, Halton, Hoyle, \& Pooley, 2004; Newton, Long, \& Sievers, 2006). Data analysis comprised the hermeneutic circle (Alvesson \& Sköldberg, 2010) where each unique individual experience was considered in relation to its meaning in the collective, which again could only be understood in respect of its constituent parts. This idea is congruent to the systems psychodynamic principle of systemic relatedness - the individual (micro-system) speaks on behalf of and represents the collective (the macro-system) (De Board, 2014).

\section{Strategies employed to ensure data quality and integrity}

Scientific rigour and trustworthiness were ensured as follows (Denzin \& Lincoln, 2005; Graneheim \& Lundman, 2003; Terre Blanche et al., 2006; Thorne, 2016). Firstly, dependability was attended to by means of scientific rigour applied to the planning and execution of the research project. Secondly, credibility was ensured by means of the authorised involvement of and intense research engagement with participants (Hirschhorn, 1997). Being OD consultants specialising in the systems psychodynamic stance, the researchers focussed, on the one hand, on the insideroutsider dialogue in the minds (Terre Blanche et al., 2006), and, on the other hand, on using themselves as research instruments to scientifically answer the research question (Clarke \& Hoggett, 2009). Confirmability was ensured by using 'member checking' (Thorne, 2016) to establish congruence in the SPLP as well as having an independent psychologists (practising in SP) scrutinise the data through which the research was found to be dependable, rich and saturated.

\section{Reporting style}

Congruent to hermeneutic phenomenology methodology, the data are presented in a narrative format. The findings contain rich data and descriptive verbatim responses on the six interview questions, and discuss the interpretation of the manifesting lived experience themes from an SP stance.

\section{Ethical considerations}

Ethical approval to conduct this study was granted by UNISA's School of Business Leadership, Research Ethics Review Committee (GSBL CRERC) on 26 July 2019, reference number: 2019_SBL_AC_011_FA. Each individual participant signed a consent form referring to their consent, maintaining anonymity and focussing on not causing harm or invading privacy (Wilson \& MacLean, 2011).

\section{Findings}

The findings contain participants' responses to the six interview questions.

\section{What motivated you to transition from clinical to organisational psychology?}

Participants' motivation in 'moving away from' clinical psychology included experiencing the work as 'routine', 'unsatisfying', 'depressing', 'too focussed on individual work', 'even boring' and 'not suited to my extravert personality'. Their motivation in 'moving towards organisational work' was stimulated by studying for an MBA and/or a 'general curiosity' towards doing something 'new', 'exiting' and 'diverse'. Over time participants became involved in doing psychometric assessment in organisations and organisational group consultancy. They became intrigued with the focus of organisations on 'growth' and 'self-development' ('so different from clinical psychology'). They were fascinated by how being involved with a team's growth actually stimulated their own self-development. Organisational work became 'more glamourous' in terms of exposure, 'connections with influential people', 'remuneration, benefits and opportunities to travel'.

\section{What were your experiences on crossing the boundary into the organisation?}

Participants found their employment interviews 'daunting', 'nerve wrecking' and 'anxiety provoking' ('I had four interviews - two with the CEO and the board!'). The 'job was sold to me as something so attractive and different from what I was used to'. They understood their psychological contract as 'to expand' and 'deepen the psychological thinking', 'especially in leadership assessment, development and coaching', executive work and systems thinking. Getting the position 'was a great boost for my ego' - 'I felt so good about myself'. Participants joined an existing OD division which meant that they 'did not have to establish the OD function in the organisation' ('which would have been impossible for me to do because I had no idea what OD was about'). They 
experienced their induction as 'friendly' and 'inviting'. Where there were other CPs already on staff, participants 'firstly paired-up with them'. Where 'I was the only clinical psychologist' they were 'treated with suspicion' and 'held at a distance'. Amongst internal clients 'fears were expressed that as a clinical psychologist I can read their minds'. 'Someone even said, we don't need your kind of psychologist - we are not mad'. Participants were strongly aware of their perceived difference - yet when they were assigned tasks, they 'could not see a difference' in 'how the different types of psychologists were assigned to internal clients' or 'were expected to perform the work'.

\section{What were your experiences on crossing the boundary into organisational psychology?}

Participants thought that OP and OD 'was common sense', that it 'focusses on keeping workers happy' - 'something I would easily pick up with my clinical training'. ('In my second year in social psychology we learned about leadership and power - I thought I know what it is about'). Similarly, they were told by colleagues that they 'will easily get the hang of it'. In taking up their role, they realised that although they may have experience of organisational psychological work, they 'had no qualification in IOP' or 'OD consulting'. They 'felt ignorant of what this field of study comprises', 'did not know the subject matter', theories, applications or 'the jargon' (such as 'performance', 'culture', 'sustainability', 'pipelines' and 'burning platforms'). They 'underestimated' and were 'overwhelmed' by 'the complexity of the organisation as a social system'. Descriptions of experiences included the following remarks: 'I felt out of my depth in working with systemic leadership complexity', 'unexpectantly nervous in facilitating sessions', 'doubting my competence as a psychologist' and 'I regretted my decision to work in organisational psychology'.

\section{How are you coping in your role as an organisational development consultant?}

Participants reported a change in focus: 'I had to give up my strong inherent focus on searching for' and 'diagnosing pathology', 'doing therapy with employees without them asking for it' and 'only focussing on individual behaviour'. 'Although I was used to work in a multi-professional team, the nature of the work and the role players are very different now' - 'the client is not a patient with a pathological diagnosis'. Thinking and working systemically were difficult - 'I was trained mostly in individual psychology'. Working with parts of large and matrix systems, 'it's interdependence', 'mirroring' and 'keeping the whole system in the mind' represented a whole new and complex way of thinking and working. The 'unpredictability' and 'fast pace of process consulting' caused high levels of performance anxiety ('so different from slow moving therapeutic sessions with time in-between to think and reflect' and 'to write reports'). The 'demand for immediate results' by powerful leaders in the system ('who are often aggressive' and 'shout at me') 'exhausted me so much'. 'I thought I was going to burn out' - 'it felt as if I will just never get it right'. 'I am still trying to find my way and understand everything'. Participants compared themselves to the IPs who 'seemed to find it all so easy'. Although 'the organisation does not offer mentorship to clinical psychologists', some of the IPs were helpful 'in providing context'. Others were 'not as friendly', as if they were 'irritated with my presence' and 'me not always understanding the complexities of the large system'. 'I have learned to reframe OD as a way of addressing' complex systemic leadership dynamics and 'coaching as a vehicle' to unleash leadership potential.

\section{What characterises your new professional role identity?}

Participants thought that they would be doing clinical work in the organisation. 'I thought I would be employed as a clinical psychologist, doing what I was trained for' - 'therapy with patients not coping with work life and stress'. 'I quickly realised that the organisation does not operate like a clinic'. 'I have to sink or swim'. They realised that their new employment contract demanded 'a dramatic change in focus' and 'a new role identity'. Participants experienced this change as 'deeply rooted in my being a psychologist' and 'in being human'. 'Becoming an OD consultant does not mean that I need to give up myself' and 'my competence'. They found themselves 'in an intensely experienced' transitional space for a 'good couple of months' filled with 'cognitive dissonance', personal and professional 'conflicts of belonging'. The feedback from colleagues and clients about their 'successes in their new role' was 'the most important factor' in making the 'emotional journey' easier, leading to a 'much more comfortable place'. ('I am still inclined to use my diagnostic lens to understand what is going on in a client system'; 'I have made peace with what I do best and use this to my advantage'; 'I have become more observant of who I am in the organisational system and to use my sensitivity and awareness to facilitate effective performance and relationships'; 'I try to be aware of what I represent in the organisation and realise that not everyone will like me and what I do'). Their new role was summarised as being a CP consulting to people and systems in the organisation on their complex and dynamic work environment, relationships and leadership matters. Final remarks related to perceived failure: 'A few of our clinical psychology colleagues did not make it', perhaps 'because the organisation did not attend to their transition' - or 'maybe we did not do enough to rescue them'.

\section{What is your contribution to the organisation?}

Participants' answers to this question were vague as if they have not thought about this before. They referred to what they 'were trained' and 'were good at' - 'facilitating deep insight', 'understanding' of and 'empathy' towards 'behavioural dynamics', and 'slowing decisions down to ensure the full picture of the manifesting dynamics are realised'. Participants who were exposed to depth psychology and psychodynamics in their training found those stances to serve as 'links between what we know and what the organisation can benefit from'. 


\section{Discussion}

The aim of the research was to provide a systems psychodynamic description of the lived experiences of a group of CPs' role transition towards becoming OD consultants.

\section{Outline of findings}

The findings are interpreted using the SP lens (Cardona, 2020) in terms of seven themes, namely Experiences of diverse and intense anxiety, Manifestation of defensive structures, Role and task transition arrest, Boundary management conflict, On being authorised and de-authorised, Fragmentation of introjected role dynamics and The Crossing: a solitary pilgrimage. The conclusion will address the relevant identity experiences.

\section{Experiences of diverse and intense anxiety}

The CPs experienced high levels of different kinds of anxieties (Curtis, 2015). Separation anxiety manifested in their feelings of being disconnected from their previous position of status and competence, followed by being overwhelmed by the unexpected new demands with the loss of stability and the known (Dejours, 2015). Transition anxiety manifested in their feelings of fear, insecurity, unfamiliarity, strangeness and not being part of the organisation - they became dependent on reassurance and avoidant of exploration of their new reality (Amado \& Elsner, 2007). Fragmentation anxiety manifested in being overwhelmed by the repetition of new demands, opinions, choices and contradictory information. Survival anxiety manifested in their feelings of fear, confusion, contradiction and chaos related to the career decision they made and the realisation that they may fail (Long, 2016). Performance anxiety manifested in their quest to be the best and to impress others (Cilliers, 2018). Persecutory anxiety manifested in their internal loneliness and isolation and free-floating anxiety manifested in their confusion in how and which role to take up in the system (Curtis, 2015). Their high levels of anxiety initially kept the CPs dependant on others' needs and approval, which manifested in difficulty to form their own opinions, affirming their own decisions, and to be in touch with their own intuition, values and wishes.

\section{Manifestation of defensive structures}

As response to their anxiety, the CPs illustrated the following array of defences (Armstrong \& Rustin, 2015; Blackman, 2004). The primal defence of splitting manifested all through the data. Their past-present split manifested in the idealisation of the organisational work (the good object) where they seemed to be seduced by their curiosity, need for self-development and status symbols, versus the denigration of clinical work (the bad object) associated with boredom. They split competence (projected onto the IOPs) and incompetence (introjected) and struggled to claim back their competence. They rationalised their experiences as 'fitting the situation' whilst at the same time resisting the impact of the transition. Regression and transference manifested in their efforts to make the present similar to the past (Amado \& Elsner, 2007). They began to see the present context as very different from what they initially expected, indicating their paranoid response, whilst the unfamiliarity of the new system is experienced as persecution (Blackman, 2004) and being under attack (Curtis, 2015).

\section{Role and task transition arrest}

The CPs experienced the transition as conflictual (Allcorn \& Stein, 2015) in many ways. Their macro-level conflict was about whether they will fit and belong in the organisation. Their meso-level conflict referred to how they assess themselves as less competent as the IO psychologists.

On the micro level, they (intellectually) experienced a sense of contradiction, imperceptibility, complexity and getting stuck in the paradox between struggling and learning. Emotionally, they were trapped between the past (representing the denigrated knowing) and the present (representing the idealised not-knowing) which had an immobilising effect, between their morals (of seeing this through) and their narcissism (of quitting) (Arundale, 2017), between their fear of failing and desperately wanting to be successful (legitimate, integrated, fulfilling a career choice with energy, desire and hope), between quick, impulsive and irrational solutions (adapted child ego state behaviour) and rationally (analytically considering what was happening to them - adult ego state behaviour) (Tudor \& Summers, 2014). In trying to solve these conflicts, they tended to over analyse their experiences leading to more doubt and confusion. Motivationally, they experienced being overwhelmed by the intellectual and emotional demands that inhibited their curiosity, reflection, creativity and risk-behaviour and kept them stuck and searching for recipes as solutions (Allcorn \& Stein, 2015). Interpersonally, they experienced conflict in terms of their acceptance by the system - they split acceptance by the other CPs (good object) and non-acceptance from some IOPs (bad object) which inhibited their sense of being supported and contained. They showed a lack of contextual empathy by not having emotional energy to listen attentively to themselves and others, realising their impact and to communicate with understanding of the situation (Amado \& Elsner, 2007).

The above rendition of CP's high levels of anxiety, defensive behaviours and conflicts can be interpreted as regressive and dysfunctional (Kilburg, 2012).

\section{Boundary management conflict}

On the boundary with the organisational identity (Allcorn \& Stein, 2015), the CPs experienced conflict between the psychological and the employment contracts (Wangithi \& Muceke, 2012). The organisational identity seduced them to enter the system to represent difference ('a special niche', 'clinical' and 'depth psychology') in the search 'to solve difficult people issues' (their psychological contract in the mind). In 
reality, the employment contract specified one primary task for all consultants. This caused performance anxiety for being offtask, incompetent, ashamed for not knowing and guilty of not delivering on the primary task (Curtis, 2015).

\section{On being authorised and de-authorised}

Initially, participants experienced being authorised (Hirschhorn, 1997) from above (by leadership) in how they were introduced and received in the organisation and their role. Whilst settling in, they experienced being de-authorised by the constraints set by the system, to not abdicate clinical work. From the side, they were initially authorised from colleagues especially other CPs on staff. From some IOPs and internal clients, they experienced and perceived to be de-authorised through the withholding of support and goodwill, the projections of incompetence and a sense of indebtedness for the honour to be recruited. They struggled to integrate the paradox of being authorised (accepted and idealised) and of being de-authorised (rejected and denigrated) at the same time and from the same parts of the system. They experienced conflict in self-authorisation (Cardona, 2020) - initially using flight away from clinical work towards OD work and once they are in the system, the reverse happened - not being accepted. This created regressive selfdoubt and longing back to 'the way it was'. In terms of the primary task, they experienced that it was more complex than anticipated and that they did not feel academically authorised to do the work. This left them overwhelmed, disillusioned and regretful towards joining the organisation. It was as if they suffered from narcissistic injury in the sense that they were not given the space to make up their own mind about their psychological autonomy (Kets De Vries, 2006).

\section{Fragmentation of introjected role dynamics}

The above-mentioned free-floating anxiety was related to the incongruence between the CPs normative, existential and phenomenal roles (Allcorn \& Stein, 2015). Their normative roles as understood when crossing the boundary into the system changed once they were assigned to clients. In their existential roles, CPs initially introjected the good object containing experiences of narcissism (Arundale, 2017) feeling special, privileged, academically superior and bringing quality to the system. This changed once they realised their lack of knowledge and experience in OD feeling conflicted, incompetent and de-authorised. This led to projections of badness onto the organisation, leadership and colleagues as non-caring, brutal and un-containing ('the organisation is not sure what it is looking for in employing clinical psychologists'). In their phenomenal role, they initially received projections of envy, superiority, privilege and being advantaged (French \& Simpson, 2015). During their struggle to cope with the above conflicts, they received projections of denigration (incompetence, moaning, not coping well, intrusive, not good-enough for the system). The above role dynamics can be referred to as fragmentation anxiety (Amado \& Elsner, 2007) which manifested in a strong sense of being emotionally overwhelmed by constantly being bombarded by conflicting information about the self and self-worth.

\section{The crossing: A solitary pilgrimage}

The transition was experienced as a potential yet painful source for individual evolution and the development of role competence (Amado \& Elsner, 2007). In their life-long maturational process towards autonomy and self-efficacy, CPs were confronted by an episode that facilitated an opportunity to face the frustration and ambivalence between what is, what might be and what is being defended against (Dias, 2016). In the interviews, CPs started to realise that they were working through a totally new experience far beyond just taking on a new job or role - it was referred to as 'a troubled birth'. They referred to this being a pronounced transition where both the complexities of the individual and the organisation collided. They mentioned being confronted with an organisational environment short of offering good-enough containment for them to struggle through aspects of their own maturation processes and its impact on applying their resilience versus their defences (Allcorn \& Stein, 2015; Dejours, 2015). Authority in the mind was active in all of their experiences, represented in the objects of psychology, OD, the corporate world, leadership and management. Authority represented a critical parent (Tudor \& Summers, 2014) intensely scrutinising their acceptance into the idealised family and not attending to the natural child's suffocation. This created an existential stuckness (Campbell \& Groenbaek, 2006) which they had to work through alone, without official support from authority figures, leading to loneliness and narcissistic injury (Arundale, 2017).

The cognitive, affective and conative experienced changerelated conflicts predicted in the literature (Allcorn \& Stein, 2015) manifested amongst these CPs. They struggled with mourning the past and processing the emotional transition towards the present and future. Instead, they took refuge in rejection and being overwhelmed. The loss inherent in any transition (Kilburg, 2012) could not be grieved as if it was not allowed or facilitated in the new system. Instead, they got stuck in their experiences of self-protective anger, grief and shame (French \& Simpson, 2015). The shame had a sense of not being good-enough and even worthless. It is hypothesised that the suppressed shame stimulated anger which they internalised (to keep up appearances of coping) and rationalised. Interestingly, the participants did not express intense sadness (depression) (Kilburg, 2012). It could be hypothesised that the experienced rejection was compensated for by holding onto their professional status in their previous roles. Interpersonally, it is as if attachment forming within the system was hard work and took a very long time (Amado \& Elsner, 2007).

The CPs in this study persevered through the transition. They referred to previous colleagues who resigned because they were overwhelmed by the situation. This was ascribed to their non-coping with the ambiguity and intense systemic demands of the OD role. Evidence was also given of intense psychosomatic symptoms and feelings of failure. It is hypothesised that the illness and failure of the system were projected onto these colleagues in the fantasy that they will export the negative on behalf of the system (Allcorn \& Stein, 2015). 


\section{Practical implications}

The findings of this study offer novel insight into the lived experiences of CPs transitioning into (for them) the new field of OP and the OD role. Whilst they may be attracted to this role for various reasons, they have limited background or training in order to take up the role with authorisation. Once organisationally inducted into the OD role, it seems as if leadership and even colleagues do not offer emotional or systemic support to the CPs. The evidence suggests that most CPs struggle through the difficulties, whilst others may just give up and resign without the problem being addressed.

\section{Limitations and recommendations}

Previous research on the phenomenon under study is not available. Therefore, no benchmark or comparison to previous or current research findings was possible. The authors had to trust their own competence and insights throughout the study. It is hoped that the researchers' empathic listening, analysis and recording of participants' lived experiences did justice to this anxiety provoking professional transition.

Research on both the conscious and unconscious experiences of CPs in OD roles is needed. The relevance of Levinson's $(1972,2008)$ guidelines for CPs in OD roles should be studied and explicated for organisational implementation.

Organisational psychology and CP should collaborate to optimise the OD function. Organisations and OD departments should be made aware of the rationale for employing CPs in OD roles, the difference in training and its application in an OD division. Furthermore, CPs should be supported, trained and coached in taking up their differently focussed OD role in an authorised capacity.

\section{Conclusion}

The CPs in this study gave in to the organisational seduction to join a powerful system with an idealised and narcissistic organisation in the mind (De Board, 2014). The organisation as an object did not realise the impact of its shadow on colleagues from a similar (psychology) and also different (clinical) background. This impact manifests as an attack on the CPs personal and professional identities of which the extent and intensity can be described as identity deformation (Kets De Vries, 2006). In their transitional space, the CPs experienced ontological insecurity (Amado \& Elsner, 2007) manifesting as being rationally inhibited, struggling in dealing with chaos, complexity and containing paradoxes (e.g. distance and closeness, outside and inside and integrating past and present), feeling emotionally overwhelmed, fragmented and fragile and motivationally immobilised. Interpersonally, they felt unaccepted, devalued, isolated, excluded and as if they have lost their autonomy.

From a systemic, psychodynamic and object relations stance, it is hypothesised that this research revealed the marriage between OP as the powerful animus object (typical of large organisations) and $\mathrm{CP}$ as anima associated with caring, support and intimacy. Animus narcissistically seduces anima to join the system, denies her historical systemic role and identity and forces her into an animus role that causes her psychological conflict and an identity crisis.

\section{Acknowledgements Competing interests}

The authors declare that they have no financial or personal relationships that may have inappropriately influenced them in writing this article.

\section{Authors' contributions}

F.C. conducted the data gathering. F.C. and S.H. shared responsibility for the theoretical and empirical work, as well as the final writing of the article.

\section{Funding information}

This research received no specific grant from any funding agency in the public, commercial or not-for-profit sectors.

\section{Data availability}

The authors confirm that the data supporting the findings of this study are available within the article.

\section{Disclaimer}

The views and opinions expressed in this article are those of the authors and do not necessarily reflect the official policy or position of any affiliated agency of the authors.

\section{References}

Akhtar, S., \& Twemlow, S. (2018). Textbook of applied psychoanalysis. London: Routledge.

Allcorn, S., \& Stein, H.F. (2015). The dysfunctional workplace. Theory, stories and practice. Columbia, MO: University of Missouri Press.

Alvesson, A., \& Sköldberg, K. (2010). Reflexive methodology. New vistas for qualitative research. Los Angeles, CA: Sage.

Amado, G., \& Elsner, R. (2007). Leaders in transition. The tensions at work as new leaders take charge. London: Karnac.

Armstrong, D., \& Rustin, M. (2015). Social defences against anxiety. London: Karnac.

Arundale, J. (2017). Identity, narcissism, and the other. Object relations and their obstacles. London: Karnac.

Berg, Z., \& Geldenhuys, D. (2013). Psychology in the work context. Cape Town: Oxford University Press.

Blackman, J.S. (2004). 101 defences. How the mind shields itself. New York, NY: Brunner-Routledge.

Brown, D. (2014). Experiential approach to organisational development. Harlow: Pearson.

Brunner, L.D., Nutkevitch, A., \& Sher, M. (2006). Group relations conferences. Reviewing and exploring theory, design, role-taking and application. London: Karnac.

Campbell, D., \& Groenbaek, M. (2006). Taking positions in the organisation. London: Karnac.

Cardona, F. (2020). Work matters. Consulting to leaders and organisations in the Tavistock tradition. London: Routledge.

Cilliers, F. (2018). The experienced impact of systems psychodynamic leadership coaching amongst professionals in a financial services organisation. South African Journal of Economic and Management Sciences, 21(1), a2091. https://doi. org/10.4102/sajems.v21i1.2091

Clarke, S., \& Hoggett, P. (2009). Research beneath the surface. Psycho-social research methods in practice. London: Karnac. 
Curtis, H. (2015). Everyday life and the unconscious mind. London: Karnac.

De Board, R. (2014). The psychoanalysis of organisations. A psychoanalytic approach to behaviour in groups and organisations. London: Routledge.

Dejours, C. (2015). Psychopathology of work. Clinical observations. London: Karnac. De Mijolla, A. (2005). International dictionary of psychoanalysis. Detroit: Thomson Gale. Denzin, N.K., \& Lincoln, Y.S. (2005). The Sage handbook of qualitative research. London: Sage.

Erikson, E.H. (1980). Identity and the life cycle. New York, NY: W.W. Norton.

Dias, E.O. (2016). Winnicott's theory of the maturational process. London: Karnac.

French, R., \& Simpson, P. (2015). Attention, cooperation, purpose. An approach to working in groups using insights from Wilfred Bion. London: Karnac.

Frosh, S. (2011). Identity after psychoanalysis. In A. Elliott (Ed.), The Routledge handbook of identity studies (pp. 58-71). London: Routledge.

Graneheim, U.H., \& Lundman, B. (2003). Qualitative content analysis in nursing research: Concepts, procedures and measures to achieve trustworthiness. Nurse Education Today, 24(2), 105-112. https://doi.org/10.1016/j.nedt.2003.10.001

Hirschhorn, L. (1997). Reworking authority: Leading and following in the post-modern organisation. London: MIT Press.

Huffington, C., Armstrong, A., Halton, W., Hoyle, L., \& Pooley, J. (2004). Working below the surface. The emotional life of contemporary organisations. London: Karnac.

Kets De Vries, M.F.R. (2006). The leader on the couch. A clinical approach to changing people and organisations. Chichester: Jossey-Bass.

Kets De Vries, M.F.R., Korotov, K., \& Florent-Treacy, E. (2007). Coach and couch. The psychology of making better leaders. London: Palgrave Macmillan.

Kilburg, R.R. (2012). Virtuous leaders. Strategy, character, and influence in the 21st century. Washington, DC: APA

Layton, L., \& Leavy-Sperounis, M. (2020). Towards a social psychoanalysis. Culture, character, and normative unconscious processes. London: Routledge.

Levinson, H. (1972). The clinical psychologist as organisational diagnostician. Professional Psychology, 3(1), 34-40. https://doi.org/10.1037/h0021493

Levinson, H. (2002). Assessing organisations. In R.L. Lowman (Ed.), The California School of Organisational Studies handbook of organisational consulting psychology. A comprehensive guide to theory, skills and techniques (pp. 315-343). San Francisco, CA: Jossey-Bass.

Levinson, H. (2008). Organizational assessment. A step-by-step guide to effective consulting. Washington, DC: APA.

Levinson, H. (2009). Consulting psychology. Washington, DC: APA.

Liebowitz, B., \& Blatter, J. (2015). On becoming a consultant: The transition for a clinical psychologist. Consulting Psychology Journal Practice and Research, 67(2), 144-161. https://doi.org/10.1037/cpb0000037

Long, S. (2013). Socioanalytic methods. Discovering the hidden in organisations and social systems. London: Karnac.

Long, S. (2016). Transforming experiences in organisations a framework for organisational research and consultancy. London: Karnac.

Lowman, R.L. (2016). Introduction to consulting psychology: Working with individual, groups and organisations. Washington, DC: APA.

Miller, A. (2018). What is a consultant clinical psychologist? Careertrend.com. Retrieved from https://careertrend.com/consultant-clinical-psychologist-26828.html
Newton, J., Long, S., \& Sievers, B. (2006). Coaching in depth. The organisational role analysis approach. London: Karnac.

Passmore, J., Peterson, D.B., \& Freire, T. (2013). The Wiley-Blackwell handbook of the psychology of coaching and mentoring. Chichester: Wiley-Blackwell.

Robbins, S.P., \& Judge, T.A. (2009). Organisational behaviour. Upper Saddle River, NJ: Pearson.

Schafer, R. (2003). Insight and interpretation. The essential tools of psychoanalysis. London: Karnac.

Schein, E.H. (1990). Organizational culture. American Psychologist, 45(2), 109-119. https://doi.org/10.1037/0003-066X.45.2.109

Schein, E.H. (1999). Process consultation revisited. Building the helping relationship. New York, NY: Abe Books.

Schein, E.H. (2013). Organisational leadership and leadership. Contextual. Retrieved from https://thehypertextual.com/2013/01/17/edgar-schein-organizationalculture-and-leadership/

Schein, E.H. (2016). Humble consulting. How to provide real help faster. New York, NY Berrett-Koehler.

Schreuder, A.M.G., \& Coetzee, M. (2010). Careers: An organisational perspective. Kenwyn: Juta.

Sekaran, U., \& Bougie, R. (2018). Research methods for business. A skill-building approach (7th edn.). New York, NY: Wiley.

Smith, R.A., Crafford, A., \& Schurink, W.J. (2015). Reflections on shifts in the work identity of research team members. SA Journal of Human Resource Management/ SA Tydskrif vir Menslikehulpbronbestuur, 13(1), Art. \#664, 1-12. https://doi. org/10.4102/sajhrm.v13i1.664

Stapley, L.F. (2006). Individuals, groups and organisations beneath the surface. London: Karnac.

Terre Blanche, M., Durrheim, K., \& Painter, D. (2006). Research in practice. Applied methods for the social sciences. Cape Town: UCT Press.

Thorne, S. (2016). Interpretive description. Qualitative research for applied practice. New York, NY: Routledge.

Tudor, K., \& Summers, G. (2014). Co-creative transactional analysis. Papers, responses, dialogues, and developments. London: Karnac.

Vansina, L., \& Vansina-Cobbaert, M.-J. (2008). Psychodynamics for consultants and managers. From understanding to leading meaningful change. Chichester: WileyBlackwell.

Verhaeghe, P. (2008). On being normal and other disorders. A manual for clinical psychodiagnostics. London: Karnac.

Viljoen, R. (2015). Organisational change and development. An African perspective. Randburg: Knowres.

Wagner, C., Kawulich, B., \& Garner, M. (2012). Doing social research. A global context. London: McGraw-Hill.

Wangithi, W.E., \& Muceke, N.J. (2012). Effect of human resources management practices on psychological contract in organisations. International Journal of Business and Social Sciences, 3(19), 117-122.

Wilson, S., \& MacLean, R. (2011). Research methods and data analysis for psychology. London: McGraw-Hill.

Winnicott, D.W. (2006). The family and individual development. London: Routledge. Retrieved from www.hpcsa.co.za 